\title{
Transduction of Swarming in Proteus mirabilis
}

\author{
By J. N. COETZEE \\ Department of Microbiology, University of Pretoria, Pretoria, \\ South Africa
}

(Received 27 December 1962)

\section{SUMMARY}

A phage able to transduce a streptomycin resistance marker in Proteus mirabilis can also separately transduce the swarming characteristic between variants of two strains of $\boldsymbol{P}$. mirabilis. Motile non-swarming variants were made to swarm on agar by incorporation of a swarming gene via a phage lysate of a swarming strain. The production of swarms by motile non-swarming variants when treated with phage lysates of other phenotypically similar strains indicated that at least three non-homologous factors control swarming. An $\mathrm{O}$ variant could also act as a donor of the swarming gene. This is because the $\mathrm{O}$ strain possesses an intact swarming centre which is masked by the absence of active flagella. This $O$ variant was transduced to swarming by phage lysates of motile non-swarming strains or of a swarming strain. The gene transduced here was concerned with the presence of flagella. Factors controlling two morphological varieties of swarming were separately transduced to suitable recipients and a locus able to modify wild-type swarms was identified.

\section{INTRODUCTION}

Many organisms may swarm under suitable conditions. Thus Salmonella (Stocker, Zinder \& Lederberg, 1953), Escherichia coli (Furness, 1958) and members of the genus Bacillus (Brown, Cherry, Moody \& Gordon, 1955) swarm on semi-solid agar. Proteus morganii swarms on $1 \%$ agar at $20-28^{\circ}$ (Rauss, 1936) and members of the genus Clostridium may swarm, particularly on moist media (Fildes, 1925). The A and $\mathrm{C}$ phases (Belyavin, 1951) of $\boldsymbol{P}$. hauseri are able to swarm vigorously on welldried nutrient agar.

Many explanations for the swarming of Proteus hauseri have been given (Lominski \& Lendrum, 1947), but the phenomenon is now generally attributed to negative chemotaxis exerted by toxins which form during the growth of the culture (Lominski $\&$ Lendrum, 1947; Hughes, 1957). These toxins have not been identified. As regards the mechanism of swarming it is agreed (Topley \& Wilson, 1955) that non-motile organisms do not swarm; active flagella are a prerequisite. Coetzee \& Sacks (1960 a) reported that certain temperate Proteus phages could transduce a streptomycin resistance marker. Swarming and non-swarming variants of some of the strains used were available (Coetzee, 1959; Coetzee \& Sacks, $1960 b$ ), and it was decided to apply transduction techniques to the study of the phenomenon of swarming in $\boldsymbol{P}$. mirabilis. 


\section{METHODS}

Media. The composition of the broth and the MacConkey-type agar employed have been described (Coetzee \& Sacks, 1960 b). In addition, a nutrient agar made and used routinely by the Department was used. In some experiments to detect abortive transductants the agar concentration in media was reduced to $0 \cdot 6 \%(\mathrm{w} / \mathrm{v})$. Plates were well dried before use. The incubation temperature was $37^{\circ}$.

Organisms. Variants of Proteus mirabilis strains 13 and 193 were used (Coetzee, 1959; Coetzee \& Sacks, $1960 a, b)$. These were 13-Y, 13- $\mathrm{W}_{1}, 13-\mathrm{W}_{7}, 13-\mathrm{Z}, 13-\mathrm{O}_{1}$, 13-Y str- $r, 193-\mathrm{Y}, 193-\mathrm{W}_{4}, 193-\mathrm{W}_{15}$. After $12 \mathrm{hr}$. incubation organism 13-Y has swarmed vigorously across nutrient agar or MacConkey plates in two or three bounds (Pl. 1, fig. 1). Variant 13-Z swarms as vigorously but in one continuous sheet of growth (Pl. 1, fig. 2). The $\mathrm{Y}$ and $\mathrm{Z}$ variants correspond respectively to the $\mathrm{A}$ and $\mathrm{C}$ phases of Belyavin (1951). Organism 193-Y swarms in compact rings and only covers half the area of a plate in the same period of time (Pl. 1, fig. 3). It hardly swarms at all on MacConkey agar. Agglutinin absorption tests (Coetzee, unpublished) showed that the $\mathbf{H}$ antigens of organisms 13 and 193 were identical while the $O$ antigens differed. This difference could possibly be reflected in the fact that strain 13 is lysed by Proteus phages 63, 78 (Coetzee, 1958), while strain 193 lacks these phage receptors. The $W$ forms of these two strains are motile and nonswarming and correspond closely to the B phase described by Belyavin (1951). They agglutinate to titre with $13-\mathrm{Y}$ or $193-\mathrm{Y} \mathrm{H}$ sera. $\mathrm{O}$ variants-i.e. non-motile strains which do not agglutinate with $\mathrm{H}$ sera (Friewer \& Leifson, 1952) are rare in these strains and only one $\left(13-\mathrm{O}_{1}\right)$ has been isolated. The $\mathrm{W}$ variants mutate to corresponding $\mathrm{Y}$ forms at low rates (Coetzee \& Sacks, $1960 \mathrm{~b}$ ) and the $\mathrm{O}$ variant does the same (Coetzee, unpublished). Strains were stored on nutrient agar slopes at $4^{\circ}$.

Phage. Phage 34/13 (Coetzee \& Sacks, 1960a) was used. Phage lysates were prepared, sterilized and titrated according to methods described in the same paper. Grown on organism 13 it has a relative efficiency of plating of unity on strain 193.

Transduction techniques. The recipient organism was washed off a stock agar slope with broth and a suspension containing $c .1 \times 10^{9}$ organisms $/ \mathrm{ml}$. made. This was done by visual comparison with a standard suspension. One ml. was then centrifuged, the supernatant discarded and the deposit mixed with $2 \mathrm{ml}$. of phage lysate of the donor strain (plaque-forming titre $c .7 \times 10^{9} / \mathrm{ml}$.). The mixture was incubated for $45 \mathrm{~min}$. Loopfuls of the contents were then streaked on both types of solid media and the plates incubated for $15 \mathrm{hr}$. In some experiments the mixtures were diluted with broth before streaking, while in others the tubes were centrifuged and the deposits streaked out as before. Controls included a lysate sterility control and a recipient control in the form of a lysate prepared on the recipient organism and mixed with that organism as above. As phage lysates of donor organisms might perhaps contain swarm-inducing toxins for the recipient (Hughes, 1957) an additional control was used. This consisted of the supernatant obtained by centrifuging a $4 \mathrm{hr}$. growth of the donor organism in soft top-layer agar used in lysate preparation, sterilized with chloroform, as were phage lysates, and mixed with the recipient organism as described above. Lysates which caused swarming of recipient organisms were treated with deoxyribonuclease and anti-phage serum as previously described (Coetzee \& Sacks, 1960a). Streptomycin resistance was transduced as described 
in the same paper. Methods used to measure phage adsorption and to detect lysogeny in transductants were also described in the paper. The character of swarms which appeared in these experiments was investigated by subculturing them on to fresh agar plates.

Serological techniques. These were as described for Proteus by Kauffmann (1951).

\section{RESULTS}

Transduction studies. Phage controls were always sterile. The two recipient controls usually showed no swarms after $15 \mathrm{hr}$. incubation (Pl. 2, fig. 4) but often produced a couple of swarms after a further 12-24 hr. No differences were noted between the two types of recipient controls. A summary of experiments performed and the nature of the swarms evoked from recipient organisms by phage lysates is presented in Table 1 . Numerous swarms were evoked from variants $13-\mathrm{O}_{1}, 13-\mathrm{W}_{1}$, and

Table 1. Summary of results of transduction experiments with phage 34/13

Donor
$13-Y$
$13-Y$ str-r
$13-O_{1}$
$13-W_{1}$
$13-W_{7}$
$13-Z$
$13-Z$

$\left.\begin{array}{c}\text { Recipient } \\ 13-O_{1}, 13-W_{1}, 13-W_{7}, 193-W_{4}, 193-W_{15} \\ 13-O_{1}, 13-W_{1}, 13-W_{7}, 193-W_{4}, 193-W_{15} \\ 13-W_{1}, 13-W_{7}, 193-W_{4}, 193-W_{15} \\ 13-O_{1}, 13-W_{7}, 193-W_{4}, 193-W_{15} \\ 13-O_{1}, 13-W_{1}, 193-W_{4}, 193-W_{15} \\ 13-O_{1}, 13-W_{1}, 13-W_{7}, 193-W_{4}, 193-W_{15} \\ 193-Y\end{array}\right\}$

Type of swarm evoked

13-Y

Z, 13-Y

13-Y swarming = discontinuous broad zone. 193-Y swarming = discontinuous compact. $\mathrm{Z}$ swarming $=$ continuous.

$13-\mathrm{W}_{7}$ by treatment with phage lysates of $13-\mathrm{Y}$ or $13-\mathrm{Y}$ str-r (Pl. 2, figs. 5, 6). No quantitative work was done, but the number of swarms produced by the above systems appeared to be of a similar order-about 20/streak. All the swarms had the 13-Y (broad zone) mode of spread. The swarm-inducing abilities of these lysates and all other lysates used in this investigation were not affected by prior treatment with deoxyribonuclease but were completely abolished by an exposure to homologous phage antiserum which reduced the plaque-forming titre below $10^{6} / \mathrm{ml}$. It is concluded that the phenomena presented are examples of phage-mediated transduction. These swarms and all other transductant swarms investigated were lysogenic for strain 13 and did not adsorb phage 34/13. This is attributed to lysogenic conversion (Coetzee, 1961). Phage lysates of 13-Y str- $r$ were also capable of transducing resistance to $1000 \mu \mathrm{g}$. streptomycin $/ \mathrm{ml}$. in these variants (Coetzee \& Sacks, $1960 \mathrm{a}$ ). These two markers are apparently not very closely linked; for no joint transductants were observed amongst 200 swarms and 300 streptomycin-resistant colonies examined. Swarms of the 13-Y (broad zone) variety were evoked from variants $13-\mathrm{W}_{1}, 13-\mathrm{W}_{7}$ by a phage lysate of $13-\mathrm{O}_{1}$. It would appear that $13-\mathrm{O}_{1}$ cannot swarm because it has lost a gene determining the presence of flagella. It retains the gene for swarming and this gene can be transduced from it to variants 13- $\mathrm{W}_{1}$ and $13-\mathrm{W}_{7}$, which are motile but do not swarm. Numerous swarms were also evoked when $13-\mathrm{O}_{1}$ was treated with phage lysates of $13-\mathrm{W}_{1}$ or $13-\mathrm{W}_{7}$. It is probable 
that in the first series as well as in the latter experiments a gene concerned with flagellation was transmitted from $13-\mathrm{Y}, 13-\mathrm{W}_{1}, 13-\mathrm{W}_{7}$ to $13-\mathrm{O}_{1}$. Swarms were evoked by phage lysates of $13-Y, 13-O_{1}, 13-W_{1}, 13-W_{7}$ from variants $193-W_{4}$ and $193-W_{15}$. The swarms were all of the $13-Y$ (broad zone) type. Recipient controls showed a few swarms after $24 \mathrm{hr}$. incubation but these were all of the 193-Y (compact) type. In years of work with strain 193 it has never swarmed in any other way than the tight-ring form previously described (Pl. 1, fig. 3). The complexity of the swarming locus was further demonstrated by the finding that swarms of the 13-Y (broad zone) variety were elicited from variant $13-W_{1}$ by treatment with phage lysate $13-W_{7}$ and vice versa. The reason why all the swarms evoked from 193-W recipients by phage lysates of strain 13 and its variants should be of the $13-Y$ (broad zone) and not the 193-Y (compact) variety may be due to the proximity of the 193 swarming-type locus and the locus responsible for loss of swarming in the two recipients, so that both loci are replaced by their alleles present on the transducing fragment. No more $W$ variants of strain 193 were available to test this hypothesis and it was not possible (see Discussion) to test the interaction of variants $193-\mathrm{W}_{4}$ and $193-W_{15}$. However, the relationship between the motile non-swarming variants means that the swarming locus in these strains is composed of at least three sites. Allogenic transformations in pneumococci are well known (Jackson, 1962) and transductions of a similar nature were first described amongst a group of galactosenon-fermenting mutants in Salmonella typhimurium (Zinder \& Lederberg, 1952). Organisms $13-\mathrm{O}_{1}, 13-\mathrm{W}_{1}, 13-\mathrm{W}_{7}, 193-\mathrm{W}_{4}, 193-\mathrm{W}_{15}$ were treated with phage lysates of organism 13-Z. Numerous swarms were produced but they were all of the 13-Y (broad zone) type. In case the transduction rate of the $\mathrm{Z}$ type of swarming was very low the transduction mixtures were centrifuged and the deposits streaked. Again only 13-Y type swarms were detected. The following hypothesis may explain these results. Swarming of Proteus hauseri is normally (Coetzee \& Sacks, $1960 \mathrm{~b}$ ) of the discontinuous 13-Y (broad zone) or 193-Y (compact) type. This swarming is controlled by a swarming locus and the 13-Y and 193-Y types are controlled by alleles $\mathrm{Y}^{+}{ }_{13}$ and $\mathrm{Y}^{+}{ }_{193}$ (Clowes, 1960). The $\mathrm{Z}$-type continuous swarming is produced when a modifier gene (the $\mathrm{Z}$ gene) mutates in a $\mathrm{Y}^{+}$genome. This $\mathrm{Z}$ locus is not closely linked to the swarmer locus $\mathrm{Y}$ or to the locus (or loci) controlling the presence of flagella. When a $13-\mathrm{Z}$ lysate is applied to $13-\mathrm{O}_{1}$ transductants acquiring the flagellar gene are selected and the newly flagellated organism then swarms because it possesses a latent swarming locus. When the 13- $Z$ lysate is applied to any of the $W$ variants transductants acquiring the swarming gene are selected, and the resultant swarms therefore manifest the $\mathbf{Y}$ character of the donor. Independent incorporation of the $\mathrm{Z}^{+}$factor remains undetected because the $\mathrm{W}$ recipients have defective swarming loci. This hypothesis was tested by making use of the very restricted swarming of 193-Y on MacConkey agar. A transduction experiment was done with $193-Y$ as recipient and a donor lysate from 13-Z (Table 1). Controls on MacConkey plates showed the restricted 193-Y swarming. The test plates had numerous large swarms after $12 \mathrm{hr}$. incubation. The periphery of $\mathbf{5 0}$ discrete swarms were subcultured on to nutrient agar and incubated overnight. Twenty-nine of the swarms were of the 13-Y (broad zone) type and 21 had the $13-\mathrm{Z}$ (continuous sheet) character. In this experiment both the flagellation and swarming loci of the recipient organism were intact. If the recipient incorporated the exogenous swarming gene then 13-Y type swarms 
resulted; when the $\mathrm{Z}^{+}$locus of the donor was incorporated, the swarming of 193-Y was modified to the $\mathbf{Z}$ pattern.

No trails of colonies (Stocker et al. 1953; Stocker, 1956) at a distance from the original streaks were detected even with the use of semi-solid media in the transduction of motility to variant $13-\mathrm{O}_{1}$. Trails could be expected if abortive transductions to swarming occurred. Because the swarms may have obscured such trails and because abortive transductions are almost always more numerous than the complete form (Ozeki, 1956) transduction mixtures were diluted before streaking. This had the effect of reducing the number of swarms/streak, but no trails of colonies were seen.

Serology. Organisms 193- $W_{4}$ and $193-W_{15}$ transduced to the 13-Y type of swarming by respectively phage lysates $13-\mathrm{Y}$ and $13-\mathrm{O}_{1}$, and organism $13-\mathrm{O}_{1}$ transduced to swarming by a lysate from $13-Y$ were examined serologically. $\mathrm{O}$ and $\mathbf{H}$ sera were prepared and agglutinin absorption tests done to detect antigenic differences between the transductants or between the latter and their parent organisms, 193-Y and 13-Y. All the $\mathbf{H}$ antigens proved identical. The $\mathrm{O}$ antigens of the 13-Y type transductants of $193-W_{4}$ and $193-W_{15}$ were identical but the $O$ sera against these strains contained antibodies which were not absorbed by strains 193 or 13 . Similarly, an $\mathrm{O}$ serum against the swarming transductant derived from $13-\mathrm{O}_{1}$ possessed antibodies which were not absorbed by strains 193 or 13. The differences between the transductants and their parent organisms were thought to result from lysogenic conversion (Coetzee, 1961).

\section{DISCUSSION}

Stocker et al. (1953) have shown that a number of distinct genes control the presence, antigenic structure and functions of flagella in Salmonella. Through lack of non-motile flagellated (paralysed) variants (Friewer \& Leifson, 1952) it was not possible to identify separate loci controlling the presence of flagella and their motility-conferring properties in this investigation. Having only one $\mathrm{O}$ variant also made it impossible to examine the possible complexity of the flagellation locus. A nice distinction was however made between the latter locus (or loci) and the swarming locus, which was found to consist of at least three sites. It was not possible to determine whether the swarming and flagella loci were linked. The Y (ring swarming) variant is the wild type of Proteus hauseri (Coetzee \& Sacks, 1960b), and this type of swarming is controlled by the swarming locus. Because phage lysates of $13-\mathrm{Z}$ (continuous swarming) transduce either the 13-Y or the 13-Z type swarming to suitable recipients, the $13-\mathrm{Z}$ phenotype is thought to result from the action of a modifier gene $\left(\mathrm{Z}^{+}\right)$on the swarming locus. These two factors are not linked closely enough to be transduced together. Bryan (1961) described a modifier gene in Pneumococci whose only detectable expression was the enhancement of activity of specific streptomycin-resistance mutations.

No experiments are reported with the use of phage lysates of variants of organism 193, because phage $34 / 13$ grown on 193 has an e.o.p. of $10^{-3}$ on organism 13. The plaques are clear. Clear plaques are also formed on all variants of 193 and no transductions have been observed. This change appears to result from a phenotypic modification of the phage (Luria, 1953) but has not been extensively studied. Thorne (1962) described a Bacillus subtilis transducing system in which the transducing phage could not be propagated on the recipient organism. 
No evidence for the occurrence of abortive transductions of swarming was encountered. This is not an exceptional finding as this type of transduction has only been reported in Salmonella (see Hartman, Hartman \& Serman, 1960) and Escherichia coli systems (Gross \& Englesberg, 1959) and not in Pseudomonas aeruginosa (Holloway \& Monk, 1959), Staphylococcus aureus (Edgar \& Stocker, 1961) or Bacillus subtilis (Thorne, 1962) transductions.

Because the flagellar antigens of organisms 193 and 13 are identical it has not been possible to analyse the genes which control $\mathrm{H}$ antigenic specificity. The system employing phage 12/57 and Proteus mirabilis strains 57 and 113 (Coetzee \& Sacks, $1960 a$ ) would possibly have been more rewarding as these strains differed in somatic and flagellar antigens (Coetzee, unpublished) but strain 113 has been lost. Initially phage 12/57 was used. It too is capable of transducing the swarming character between $\mathrm{Y}$ and $\mathrm{W}$ variants of strain 57 but, as no other variants of this strain could be selected, the present system was chosen. Indeed the paucity of variants and the very restricted host-ranges of the transducing phages are serious obstacles in the transduction studies with $\boldsymbol{P}$. hauseri.

This work has shown that phage $34 / 13$ can independently transduce a streptomycin-resistance marker, a flagellation marker, the swarming-type and $\mathrm{Z}$ markers. It may now be classed as a phage capable of general transduction.

Acknowledgement is made to Miss G. Pernet and Mrs C. J. Boshoff for technical assistance rendered. The author was in receipt of a grant from the South African Council for Scientific and Industrial Research.

\section{REFERENCES}

Belyavin, G. (1951). Cultural and serological phases of Proteus vulgaris. J. gen. Microbiol. $5,197$.

Brown, E. R., Cherry, W. B., Moody, M. D. \& Gordon, M. A. (1955). The induction of motility in Bacillus anthracis by means of bacteriophage lysates. J. Bact. 69, 590.

BRYAN, B. E. (1961). Genetic modifiers of streptomycin resistance in pneumococcus. J. Bact. 82, 461.

Clowes, R. C. (1960). Fine genetic structure as revealed by transduction. In Microbial Genetics. Symp. Soc. gen. Microbiol. 10, 92.

Coetzee, J. N. (1958). The characterization of a series of Proteus bacteriophages. $S$. Afr. J. Lab. clin. Med. 4, 147.

Coetzee, J. N. (1959). Some properties of a morphological variant of a strain of Proteus vulgaris. S. Afr. J. Lab. clin. Med. 5, 17.

Coetzee, J. N. (1961). Lysogenic conversion in the genus Proteus. Nature, Lond. 189, 946.

Coetzee, J. N. \& SAcks, T. G. (1960a). Transduction of streptomycin resistance in Proteus mirabilis. J. gen. Microbiol. 23, 445.

Coetzee, J. N. \& SACKs, T. G. (1960b). Morphological variants of Proteus hauseri. J. gen. Microbiol. 23, 209.

EDGar, J. B. \& Stocker, B. A. D. (1961). Metabolic and genetic investigations of nutritionally exacting strains of Staphylococcus pyogenes. Nature, Lond. 191, 1121.

Findes, P. (1925). Tetanus. 1. Isolation, morphology and cultural reactions of $B$. tetani. Brit. J. exp. Path. 6, 62.

Friewer, F. I. \& Leifson, E. (1952). Non-motile flagellated variants of Salmonella typhi-murium. J. Path. Bact. 64, 223.

FurNess, G. (1958). The transfer of motility and tyrosine requirement to Escherichia coli strain B by recombination with $E$. coli strain $\mathrm{x} 12$. J. gen. Microbiol. 18, 782 . 
Journal of General Microbiology, Vol. 33, No. 1

Plate 1
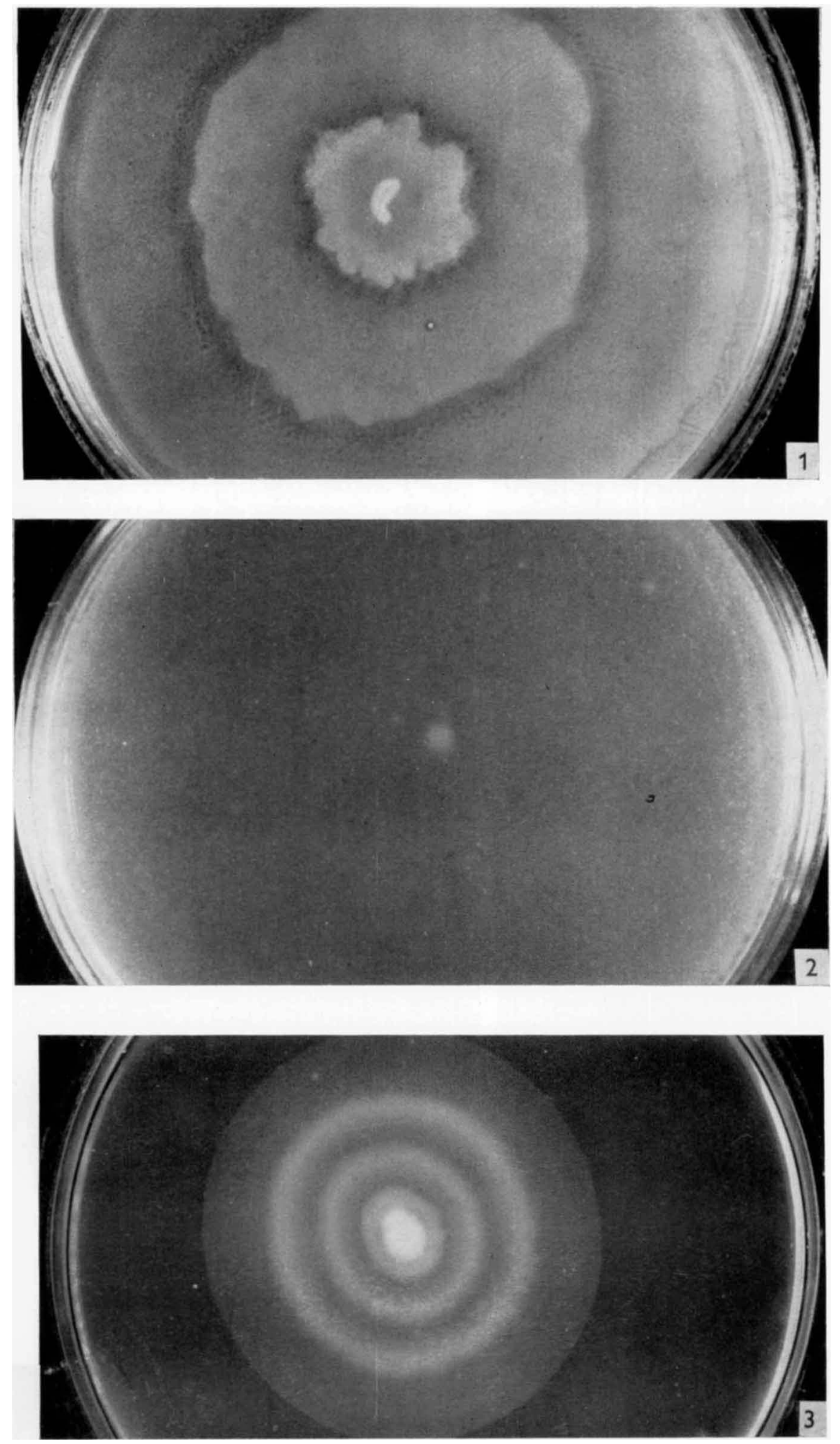
Journal of General Microbiology, Vol. 33, No. 1

Plate 2
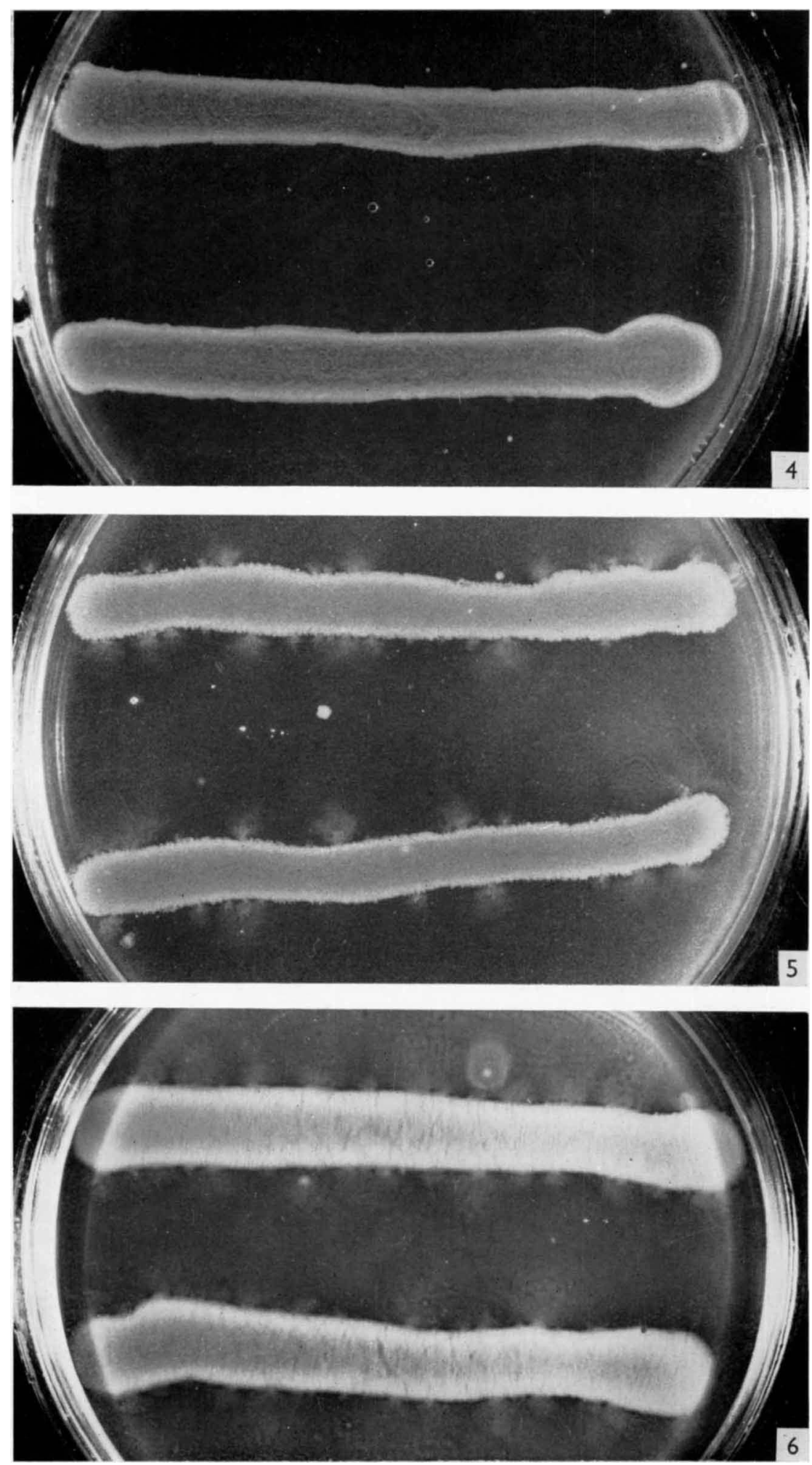

J. N. COETZEE 
Gross, J. \& Englesberg, E. (1959). Determination of the order of mutational sites governing L-arabinose utilization in Escherichia coli $\mathrm{B} / \mathrm{r}$ by transduction with phage Plbt. Virology, 9, 314.

Hartman, P. E., Hartman, Z. \& Šrman, D. (1960). Complementation mapping by abortive transduction of histidine requiring Salmonella mutants. J. gen. Microbiol. 22, 354.

Holloway, B. W. \& Monk, M. (1959). Transduction in Pseudomonas aeruginosa. Nature, Lond. 184, 1426.

Hughes, W. H. (1957). A reconsideration of the swarming of Proteus vulgaris. J. gen. Microbiol. 17, 49.

JACKson, S. (1962). Genetic aspects of capsule formation in the pneumococcus. Brit. med. Bull. 18, 24.

Kauffmann, F. (1951). Enterobacteriaceae. Copenhagen: Einar Munksgaard.

Lominski, I. \& Lendrum, A. C. (1947). The mechanism of swarming of Proteus. J. Path. Bact. 59, 688.

Luria, S. E. (1953). Host-induced modifications of viruses. Cold. Spr. Harb. Symp. quant. Biol. 18, 237.

OzEKI, H. (1956). Abortive transduction in purine-requiring mutants of Salmonella typhimurium. Genetic Studies with Bacteria. Publ. Carneg. Instn, no. 612, p. 97.

RaUss, K. (1936). The systematic position of Morgan's bacillus. J. Path. Bact. 42, 183.

Stocker, B. A. D. (1956). Abortive transduction of motility in Salmonella; a nonreplicated gene transmitted through many generations to a single descendant. J. gen. Microbiol. 15, 575 .

Stocker, B. A. D., Zinder, N. D. \& Lederberg, J. (1953). Transduction of flagellar characteristics in Salmonella. J. gen. Microbiol. 9, 410.

Thorne, C. B. (1962). Transduction in Bacillus subtilis. J. Bact. 83, 106.

Topley \& Wilson. Principles of Bacteriology and Immunity, 4th ed. (1955). Ed. by G. S. Wilson \& A. A. Miles. London: Edward Arnold.

Zinder, N. D. \& Lederberg, J. (1952). Genetic exchange in Salmonella. J. Bact. 64, 679 .

\section{EXPLANATION OF PLATES}

(All figures life size.)

Prate 1

Fig. 1. Organism 13-Y inoculated at centre of nutrient agar plate and incubated for $15 \mathrm{hr}$. at $37^{\circ}$.

Fig. 2. Organism $13-\mathrm{Z}$ inoculated at centre of nutrient agar plate and incubated for $15 \mathrm{hr}$, at $37^{\circ}$. Fig. 3. Organism 193-Y inoculated at centre of nutrient agar plate and incubated for $15 \mathrm{hr}$. at $37^{\circ}$.

\section{Plate 2}

Fig. 4. A 13- $\mathrm{W}_{1}$ recipient control on nutrient agar. No swarms present after $15 \mathrm{hr}$. at $37^{\circ}$.

Fig. 5. Organism $13-\mathrm{O}_{1}$ treated with a $13-\mathrm{Y}$ phage lysate. Many small discrete swarms and a few large swarms are present on MacConkey agar after $15 \mathrm{hr}$. at $37^{\circ}$.

Fig. 6. Organism 13- $\mathrm{W}_{7}$ treated with a phage lysate of 13-Y. Swarms have merged but their points of origin can be seen. Nutrient agar after $12 \mathrm{hr}$. at $37^{\circ}$. 